\title{
Tensile behaviour identification in Ultra-High Performance Fibre Reinforced Cementitious Composites: indirect tension tests and back analysis of flexural test results
}

\author{
Francesco Lo Monte $\mathbb{D} \cdot$ Liberato Ferrara
}

Received: 28 April 2020/ Accepted: 31 October 2020/Published online: 26 November 2020

(C) The Author(s) 2020

\begin{abstract}
Within the framework of the European Programme Horizon 2020, the Research Project ReSHEALience is currently running with the objective of developing a new approach for the design of structures exposed to extremely aggressive environments, based on Durability Assessment based Design and Life Cycle Analysis. To this aim, new advanced Ultra-High Performance Fibre Reinforced Cementitious Composites with improved durability, called Ultra-High Durability Concretes, are under investigation to characterize their tensile response in both ordinary and very aggressive conditions. In this context, the first step is to develop an effective approach for identifying the main parameters describing the overall behaviour in tension. In the present study, indirect tension tests have been performed via two techniques, based on Double Edge Wedge Splitting and 4-Point Bending Tests. Starting from the test results, a combined experimental-numerical identification procedure has been implemented in order to evaluate the effective material behaviour in direct tension in terms of stress-strain law. In the paper, the mechanical characterization for the reference mix is
\end{abstract}

F. Lo Monte $(\bowtie) \cdot$ L. Ferrara

Department of Civil and Environmental Engineering,

Politecnico di Milano, Milan, Italy

e-mail: francesco.lo@polimi.it

L. Ferrara

e-mail: liberato.ferrara@polimi.it reported so to describe the identification procedure adopted.

Keywords ReSHEALience - Ultra-High Durability Concrete-UHDC · Tensile constitutive behaviour . Strain-hardening $\cdot$ Identification

\section{Introduction}

\subsection{Research framework}

Within the framework of the European Programme Horizon 2020, the Research Project ReSHEALience has been launched in 2018 involving 14 Partners and 3 linked third parties all around Europe. The main objective is to develop a durability-oriented structural approach for both ordinary and extremely aggressive environments, based on the concepts of Durability Assessment based Design (DAD) and Life Cycle Analysis (LCA).

The scope of the project is pursued via two different steps: (1) development of new advanced cementitious materials with improved durability, which will be hereafter called Ultra-High Durability Concretes (UHDC [1]), and (2) formulation of explicit methods for directly determining the target durability performance at the structural level. 
So far, the first step has been accomplished, by formulating tensile strain-hardening Ultra-High Performance Fibre Reinforced Cement Composites (UHPFRCC) with engineered self-healing capability (obtained in the prelimiary step of the project by adding crystalline admixture). This latter property, together with the extensive multiple cracking characterized by very small crack openings, makes it possible to significantly increase the durability of these cementitious composites.

The composition of such materials is based on the rather established knowledge about UHPFRCC; in particular, it is used a combination of cement and slag, small aggregates (maximum size of $2 \mathrm{~mm}$ ) and steel fibres at dosages higher than $1.5 \%$ by volume.

Strain-hardening behaviour in tension is made possible by fibres, which allow in uniformly loaded elements a multiple stable crack propagation following the onset of the first crack, till localization of a single unstable propagating crack occurs [2]. This property is instrumental in keeping crack opening within very low values and it is based on the micromechanical design of the mix, balancing crack-tip toughness and fibre pull-out work [3-5].

It is worth noting that, as also shown in the following, strain-hardening behaviour generally does not translate into multiple cracking in notched specimens, since load conditions are not uniform. In such case, the hardening response following the formation of the single main crack in the notched section (where stress intensification takes place) is observed.

The benefit brought in by multi-cracking in terms of crack opening has been shown by preliminary flexural tests performed on un-notched specimens for the mix described in the following (see Table 1). Cracks narrower than $100 \mu \mathrm{m}$ were generally observed for tensile strain of $2 \%$, this value corresponding to the design yielding strain of conventional steel reinforcement. Such feature can significantly improve the durability of concrete structures, by reducing the penetration of aggressive agents also in the cracked state and not merely relying upon a reduced permeability in the un-cracked one [6]. Furthermore, the positive interaction between crack tightness and material composition also results into a high propensity to autogenous self-healing, with synergetic effects on the enhancement of material and structural durability [7-12].

Within this context, the main target of the present study is to describe the identification procedure adopted for estimating the constitutive law in direct tension for this kind of materials, starting from indirect tension tests (as for example bending). Such task is not trivial, but it is instrumental for moving from the experimental scale to the structural one, making possible a reliable structural design.

\subsection{Tensile characterization of UHPFRCC}

The identification of the stress-strain law in direct tension is of primary importance to generalize the results coming from experimental testing, and several approaches can be found in the literature [13-18]. In this regards, direct tensile test is generally considered the most reliable test, but it is rather complex to be implemented and very sensitive to possible defects and eccentricity in loading [16]. On the other hand, flexural test is much easier to be implemented, proving also a much higher repeatability. This latter test, however, is characterized by sizable structural effects

Table 1 UHDC mix compositions and specimen production

\begin{tabular}{lc}
\hline Constituents $\left[\mathbf{k g} / \mathbf{m}^{3}\right]$ & XA-CA \\
\hline CEM I 52.5 & 600 \\
Slag & 500 \\
Water & 200 \\
Steel fibres & 120 \\
Sand (0-2 mm) & 982 \\
Superplasticizer & 33 \\
Crystalline adm. & 4.8 \\
\hline
\end{tabular}
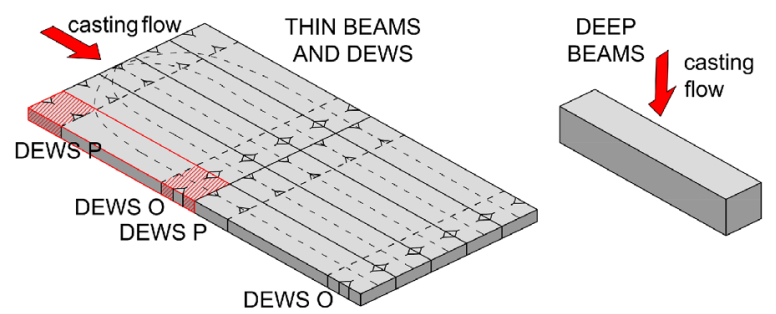
caused by stress redistribution in the section, thus making rather difficult the backward identification of the material mechanical properties $[16,18]$.

Referring to four possible concrete mixes, the qualitative scheme of the mechanical behaviour is reported in Fig. 1 (adapted from [19]) in case of hardening or softening response in direct tension, 1D or $2 \mathrm{D}$ bending. It can be observed as a concrete mix characterized by softening behaviour in direct tension can translate into a hardening one in 1D bending, thanks to the stress redistribution in the section (because of the inherent redundancy, this being the so-called structural effect). This is even more evident in the case of $2 \mathrm{D}$ bending, thanks to stress redistribution in different transverse directions of the slab, depending on restraints and loading conditions.

This is extremely advantageous in structural behaviour, providing more and more ductility for increasing level of internal and external redundancy. On the other hand, this makes very tricky to define the direct tension constitutive law of the material, starting from the results of bending tests on beams or slabs.

This is demonstrated by means of the simple example of Fig. 2, where three rather different constitutive models in direct tension (Fig. 2a) lead to very close loading curves in bending (Fig. 2b), in which the gap among the curves is comparable with the typical scattering in test results.

It is worth noting as the three constitutive curves in Fig. 2a are characterized by hardening, perfect plastic or softening behaviour, respectively, enlightening as the identification of material stress-strain law from bending is very difficult due to the intrinsic redundancy of the problem.

In the present paper, the approach developed for the characterization of the tensile "constitutive" behaviour of a UPFRCC (referred as UHDC in the following) and for the identification of the main mechanical parameters is described. The approach is based on a combination of (a) different experimental techniques and (b) numerical procedures. In particular, (1) Double Edge Wedge Splitting (DEWS) and (2) 4-Point Bending Tests (4PBT) on two specimen geometries have been used.

The approach described allows the estimation of the constitutive law in direct tension starting from indirect tests. On the other hand, the analysis of durabilityrelated properties and self-healing capability are part of a further step of the experimental campaign not presented in this paper.

\section{Experimental program}

\subsection{Concrete mix}

The study is based on a reference UHDC mix (XACA) containing crystalline Penetron Admix ${ }^{\circledR}$, whose effect on the overall performance of concrete has been investigated elsewhere [20, 21]. Cement type CEM I 52.5 and slag have been used as a binder and sand with a maximum size of $2 \mathrm{~mm}$ has been adopted, according to the proportions reported in Table 1 .

The water to binder ratio is 0.18 and superplasticizer has been added to get the correct rheology during

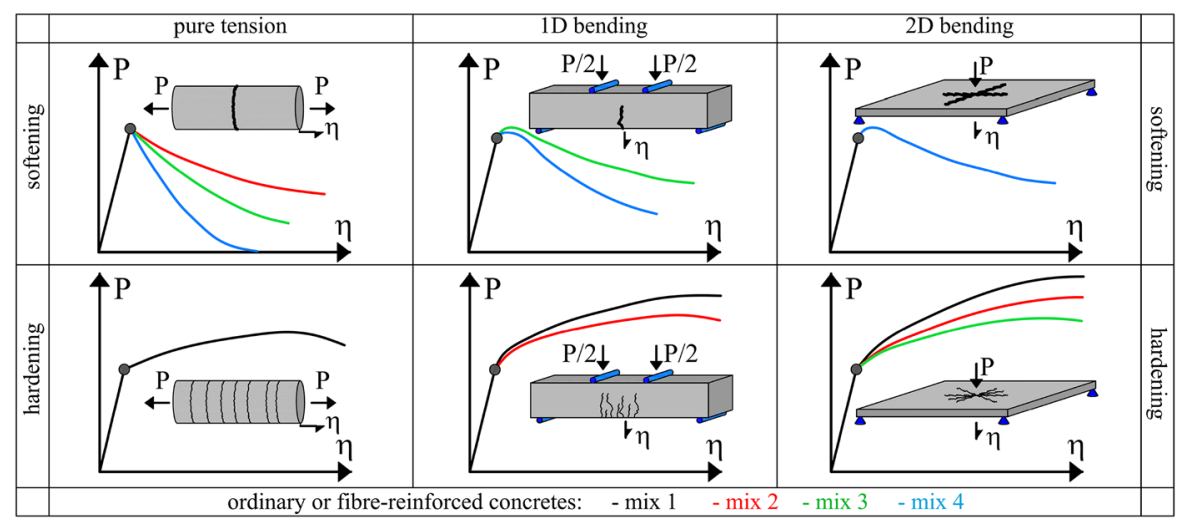

Fig. 1 Schematic representation of hardening and softening behaviour in tension and bending, referring to four possible concrete mixes. Adapted from [20] 

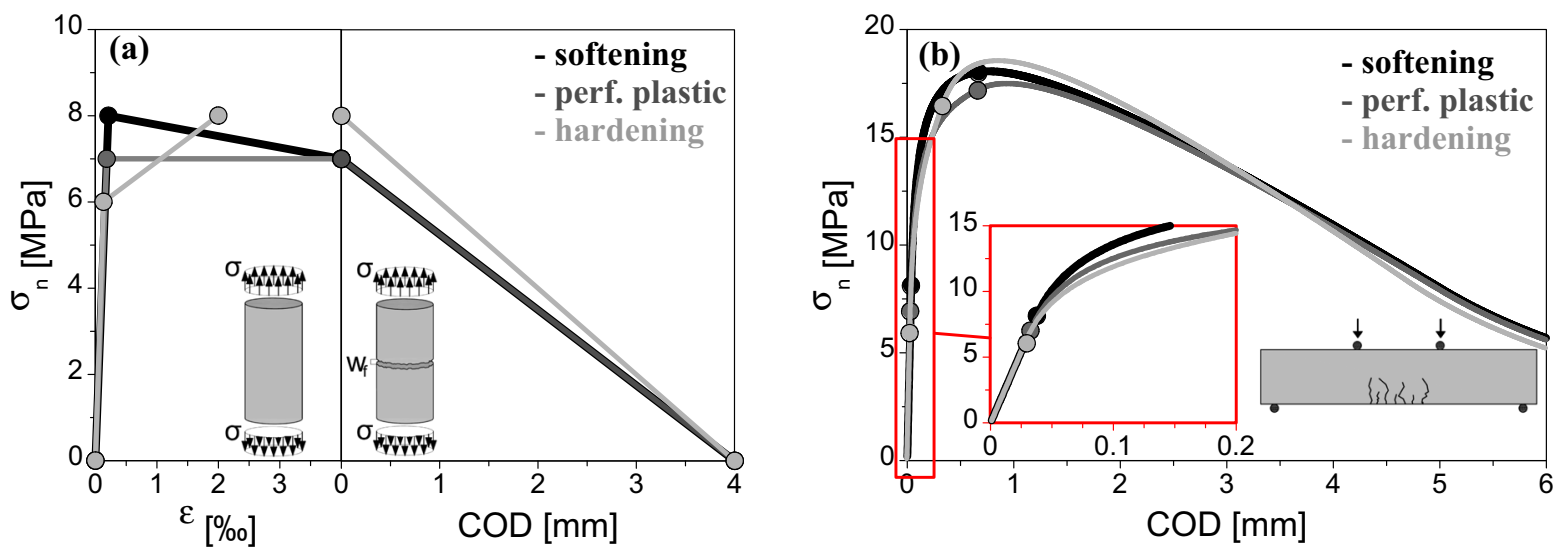

Fig. 2 Three constitutive laws in tension (a) and corresponding loading curves in bending (b) (obtained by sectional integration according to the procedure described in Fig. 4a)

casting, studied for fostering fibre alignment with pouring flow. Straight brass-plated fibres (tensile strength $\mathrm{f}_{\mathrm{t}} \geq 2400 \mathrm{MPa}$, length $\mathrm{l}_{\mathrm{f}}=20 \mathrm{~mm}$ and diameter $\mathrm{d}_{\mathrm{f}}=0.22 \mathrm{~mm}$ ) in the content of $1.5 \%$ by volume have been introduced in order to provide the strainhardening behaviour in tension. Prismatic beams and thin slabs been cast according to the scheme reported within Table 1.

\subsection{Test setups and specimen geometries}

As mentioned above, in order to study the multiplecracking ability of the UHDC mix at issue, mechanical characterization has been performed via different testing methods so to investigate possible scale effects and to calibrate the stress-strain law in direct tension.

The two different testing methodologies employed are (see also Fig. 3):

- Double-Edge Wedge Splitting (DEWS) tests on $100 \cdot 100 \cdot 25 \mathrm{~mm}^{3}$ thick tiles;

- 4-Point Bending Tests (4PBT) on Deep Beams DB $\left(l \cdot w \cdot h=500 \cdot 100 \cdot 100 \mathrm{~mm}^{3}\right)$ and on Thin Beams - TB $\left(l \cdot w \cdot h=500 \cdot 100 \cdot 25 \mathrm{~mm}^{3}\right)$.

DEWS is a modified splitting test in which two main features make tensile stresses more evenly distributed in the ligament. In particular, (a) the notch is introduced at the ligament ends $(7.5 \mathrm{~mm}$ in the present case) and (b) $45^{\circ}$-inclined surfaces are cut (10 mm-high in the case at issue) for the positioning of the loading blade. Thanks to these two aspects, DEWS test is deemed to yield straightforward the tensile stress versus crack opening "constitutive" behaviour of the UHDC [22]. This makes the test suitable to check the strain-hardening tensile behaviour of concrete mixes and to calibrate the effective stress-strain $(\sigma-\varepsilon)$ law. Furthermore, since the test is performed on notched specimens, the correct evaluation of the first cracking stress is much easier.

As shown by the red segments in Fig. 3, the displacement across the ligament is measured via three Linear Voltage Displacement Transducers (LVDTs), two of them positioned on the front face and one on the rear face, thus monitoring any possible relative rotation of the two halves of the sample. LVDTs are fixed to metal platelet (this causing an offset, $\Delta_{\text {trans }}$, between the plane of measurement and the edge of the specimen), which are glued to the samples in the positions reported in Fig. 3. The test is strokedisplacement controlled.

For the characterization in bending, 4PBT on unnotched specimens are adopted, since it allows to investigate multiple cracking in the central region $L_{\mathrm{o}}$, where the bending moment is constant. During loading, (a) the relative vertical displacement of the mid-span section with respect to the supports and (b) the Crack-Opening Displacement-COD across the central region of the specimen are monitored via two LVDTs each, as represented by red segments in Fig. 3. LVDTs are fixed to metal platelets (this causing an offset, $\Delta_{\text {trans, }}$, between the plane of measurement and the edge of the specimen), which are glued in the positions reported in the figure. 

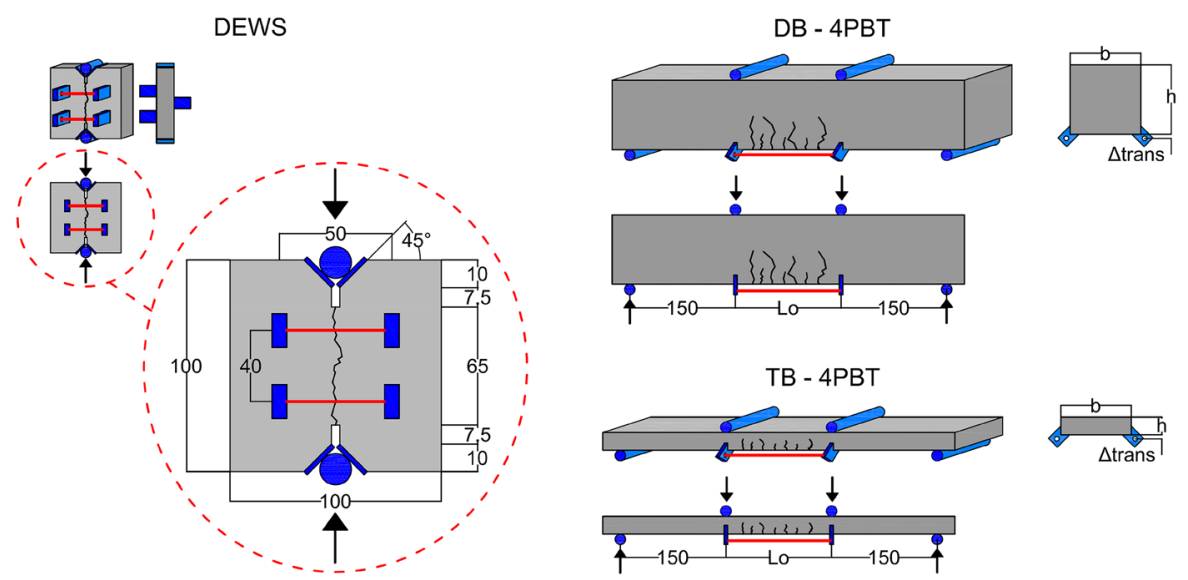

Fig. 3 Scheme for DEWS on 100 100.25 $\mathrm{mm}^{3}$ tiles a nd 4 PBT on thin beams $(\mathrm{TB}, \mathrm{h}=25 \mathrm{~mm})$ and deep beams $(\mathrm{DB}, \mathrm{h}=100 \mathrm{~m})$. $\mathrm{L}_{\mathrm{o}}=150 \mathrm{~mm}, \Delta_{\text {trans }}=$ offset between plane of LVDTs' measurement and specimen edge

More complex arrangements of transducers could be also employed in order to better determine the crack localization point [18]. In the present study, the test is stroke-displacement controlled.

The characterization on thin beams has been performed addressing a specific structural application (namely, a water tank made with precast $30 \mathrm{~mm}$-thick slabs [23]), in order to verify the influence on the tensile constitutive response of the material played by (a) the well-known scale-effect and (b) the likely wall effect induced orientation of the fibres.

As reported in the insert of Table 1, deep beams are cast in individual moulds, whereas thin beams are cut from larger cast slabs $\left(1000 \times 500 \times 25 \mathrm{~mm}^{3}\right)$. In this latter case, slabs are cast allowing the flow of the fresh self-consolidating mix along the longer side, this being fostered by slightly inclining the mould during concrete pouring thus obtaining an almost 1D flow.

Thin beam specimens are then cut with their longitudinal axis parallel to the flow, which is also likely to coincide with the expected flow-induced alignment of the fibres (as also experimentally investigated in [24-26]) according to the sketch shown in the insert of Table 1.

Even though thin beams better represent the mechanical response of the target structural application, deep beams are also tested as a common reference among all the partners within ReSHEALience consortium. The different partners, in fact, are working on several pilots of the Project, with rather different structural layouts. Furthermore, the geometry of deep beams is more widely used in similar experimental campaigns in the literature.

Specimens for DEWS tests are obtained from thin beams. The ligament cross-sections are defined by cutting grooves and notches in the square tile specimens via a water-cooled diamond blade. The ligament is pre-induced in such a way to result either orthogonal or parallel to the aforementioned alignment of the fibres, in order to have a lower and upper bound for the tensile constitutive response of the investigated mix.

All tests are performed after at least 90 days from casting, in order to allow slag to develop the maximum possible long term hydration and pozzolanic activity, as compatible with the low water/binder ratio employed. In the curing period, all samples are stored in climate chamber (R.H. $=90 \%, \mathrm{~T}=20^{\circ} \mathrm{C}$ ).

\section{Identification of the mechanical parameters in tension}

The "qualitative" behaviour in direct tension and in bending for strain-hardening materials is sketched in Fig. $4 \mathrm{a}$, where it is shown as, after the initial elastic branch, cracking occurs in correspondence of the first cracking stress, $\sigma_{\mathrm{cr}}$. Afterwards, the bridging-effect of fibres crossing the cracks takes place, thus allowing to further increase the external load. In this phase, for unnotched specimens, tensile deformation is smeared into several small cracks and can be addressed as a smeared strain. When crack localization occurs, the further tensile deformation concentrates into a single 
crack and the external load starts decreasing. It is worth noting that in the general case $\sigma_{\mathrm{pk}, \mathrm{b}}>\sigma_{\mathrm{pk}, \mathrm{t}}$, where $\sigma_{\mathrm{pk}, \mathrm{b}}$ and $\sigma_{\mathrm{pk}, \mathrm{t}}$ are the peak stresses in bending and in direct tension, respectively (Fig. 4a).

The evaluation of $\sigma_{\mathrm{cr}}$ and $\sigma_{\mathrm{pk}, \mathrm{t}}$ (and of the correspondent strains, $\varepsilon_{\mathrm{cr}}$ and $\varepsilon_{\mathrm{pk}, \mathrm{t}}$ ) is of primary importance, since they describe the multiple cracking phase. However, both $\sigma_{\mathrm{cr}}$ and $\sigma_{\mathrm{pk}, \mathrm{t}}$ can be hardly identified in $4 \mathrm{PBT}$ due to the very smooth transition among the elastic, the hardening and the softening branches. As mentioned in the introduction, this is because of the stress redistribution across the specimen height (the so-called, structural effect). On the other hand, a reliable estimation of $\sigma_{\mathrm{cr}}$ and $\sigma_{\mathrm{pk}, \mathrm{t}}$ is possible thanks to DEWS, since the stress state is almost homogeneous along the ligament [22].

Hence, in order to estimate the behaviour in direct tension of the investigated UHDC (as representative of the broad HPFRCC category), a combined experimental-numerical approach has been herein adopted. Aimed at exploring the influence of some influencing aspects, four different numerical analyses have been implemented: (1) 1D approach based on sectional integration, (2) 1D analytical approach based on a quadrilinear law in tension [16], (3) 1D approach with perfect-plastic law in tension and (4) 3D Finite Element analysis (implemented in the commercial software Abaqus).

For all the four numerical approaches, the first step is the calibration of the effective stress-strain $(\sigma-\varepsilon)$ constitutive tensile law on the basis of the DEWS test results. Afterwards, each of the four numerical analysis is implemented to simulate the mechanical response in the flexural test.
Regarding the first numerical procedure, the nominal stress-Crack Opening Displacement $\left(\sigma_{\mathrm{n}}-\right.$ COD) in bending has been computed numerically via stress integration across specimen thickness, under the assumption of plane sections. As shown in Fig. 4a this has been implemented through 4 steps of analysis: (1) for any values of the sectional curvature $\chi_{i}$ between 0 and the ultimate curvature, the strain profile in the section is defined for an arbitrary value of the axial elongation at the centroid $\varepsilon_{0}$, (2) the stress profile $\sigma[\varepsilon(\mathrm{z})]$ is worked out using the constitutive law given as input to the procedure, (3) the correct value of $\varepsilon_{0}$ is calculated by enforcing the equilibrium in terms of axial force (namely, imposing the external axial force, $\mathrm{N}$, equal to the internal axial force, $N_{i}=\int \sigma \cdot d A$ ), and (4) the internal moment is evaluated by stressintegration in the section and the nominal stress $\sigma_{n}$ at the most stressed fibre is calculated together with the correspondent COD.

The stress-strain $(\sigma-\varepsilon)$ constitutive law in direct tension (green curve in Fig. 5a) has been approximated by a bilinear curve in the pre-localization regime (blue and black straight lines in Fig. 4a), followed by a power law of order -0.5 describing the post-localization behaviour (grey curve in Fig. 4a). Such assumed law is uniquely described by 5 parameters: the elastic modulus $E$, the first-cracking stress $\sigma_{\mathrm{cr}}$, the peak stress in tension $\sigma_{\mathrm{pk}, \mathrm{t}}$, the strain at the peak stress $\varepsilon_{\mathrm{pk}, \mathrm{t}}$ and the ultimate strain for which the stress is nil, $\varepsilon_{\mathrm{ul}}$.

The elastic modulus has been calibrated in order to match the initial flexural stiffness in 4PBT, while all the other parameters have been calibrated on the basis of the DEWS test results. In particular, $\sigma_{\mathrm{cr}}$ has been
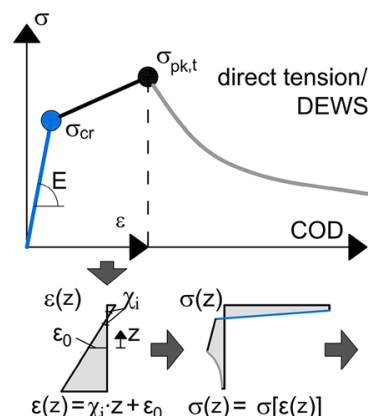

(1)
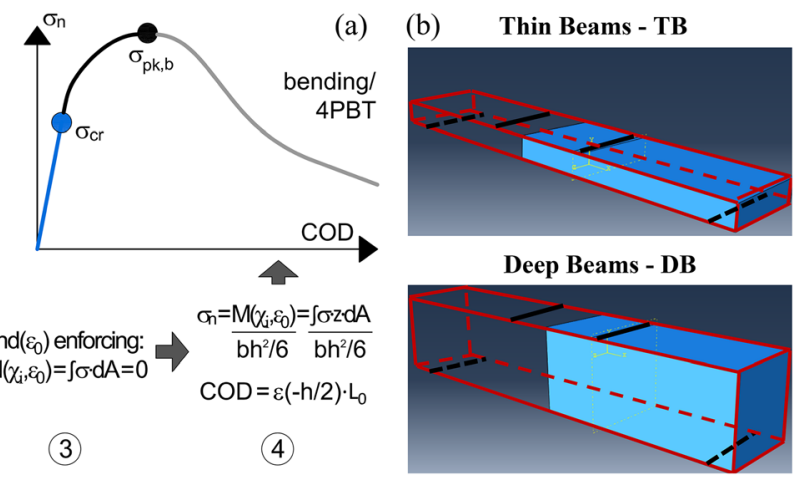

Fig. 4 Qualitative $\sigma_{\mathrm{n}}$ - COD curves in tension/bending and scheme of numerical procedure in 1D setional integration approach (a), and geometrical models implemented in 3D finite element simulations on thin and deep beams (b) 
estimated on DEWS_P with fibres parallel to the ligament (being negligible the role played by fibres), while $\sigma_{\mathrm{pk}, \mathrm{t}}, \varepsilon_{\mathrm{pk}, \mathrm{t}}$ and $\varepsilon_{\mathrm{ul}}$ have been estimated on the bases of DEWS_O with fibres orthogonal to the ligament (where fibre crack-bridging is effective).

It is worth remarking that the COD-strain conversion is performed with reference to the LVDT gauge length, this translating in the assumption of non-linear hinge in the multiple-cracking region [16-18]. This numerical procedure is called in the following as $1 D$ approach (1) and it is represented in the plots of Figs. 5 and 6 by a green curve.

The second approach consists in the analytical procedure described in [16], in which the stress-strain law in tension is assumed to be described by four segments (orange curve in Fig. 5a). This mechanical model is uniquely defined by the same five parameters above-described $\left(E, \sigma_{\mathrm{cr}}, \sigma_{\mathrm{pk}, \mathrm{t}}, \varepsilon_{\mathrm{pk}, \mathrm{t}}\right.$ and $\varepsilon_{\mathrm{ul}}$. ) plus a further parameter, namely the crack opening $\mathrm{w}_{\mathrm{d}}$ corresponding to the stress $\sigma_{\mathrm{pk}, \mathrm{t}} / 3$ in the post-localization branch. Thanks to the explicit analytic formulation provided in [16], the method is rather easy to be implemented allowing the calculation of the bending moment-curvature relationship, once the constitutive law in tension has been defined. This approach is called in the following as $1 D$ approach (2) and it is represented in the plots of Figs. 5 and 6 by an orange curve. Obviously, implementing in the previous integration procedure (ID approach (1)) the same quadrilinear $\sigma-\varepsilon$ law in tension leads to exactly the same results of the analytical approach (1D approach (2)).

(a)

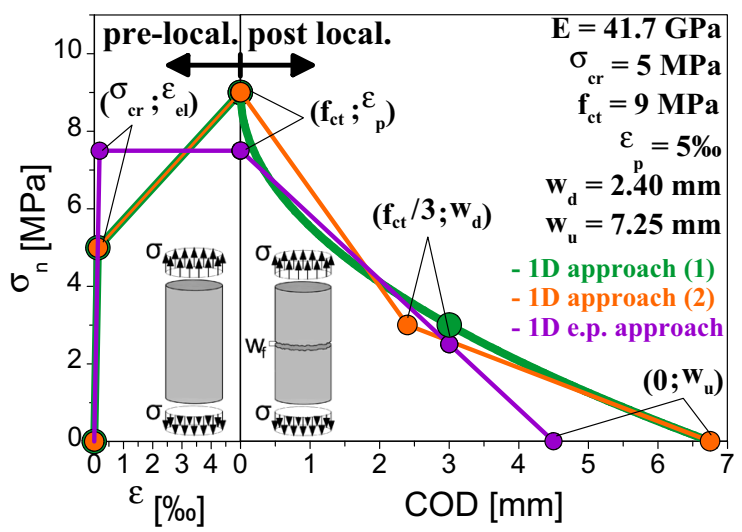

In the third analysis, it is explored the possibility of adopting a perfect-plastic behaviour in the pre-localization phase (much easier to be handled for structural design purposes), as represented in the plots of Figs. 5 and 6 by the violet curve. This constitutive law can be implemented in both the sectional integration approach and the analytical method.

Finally, the fourth approach consists in a 3D Finite Element simulation performed via the commercial software Abaqus. In the 3D simulation, 8-nodes linear hexahedron elements of regular shape are adopted. Using the same regular shape for all the finite elements allows for the implementation of the constitutive law in the stress-displacement framework, this providing a much higher numerical stability. Stress and displacement, in fact, are directly proportional to the mesh characteristic length, which in Abaqus is determined as the geometric average of the three dimensions of the mesh elements. Exploiting the symmetry of the problem, just one half of thin and deep beams is modelled, as shown in Fig. 4b. The constitutive law adopted for 3D Finite Element analyses is the same assumed for the 1D approach (1) (namely, the green curve of Fig. 5a) and the correspondent results on 4PBT simulations are represented by red curves in Fig. 6.

\section{Results and discussion}

The experimental results on DEWS are reported in grey and black curves in Fig. $5 \mathrm{~b}$ in terms of $\sigma_{\mathrm{n}}-\mathrm{COD}$

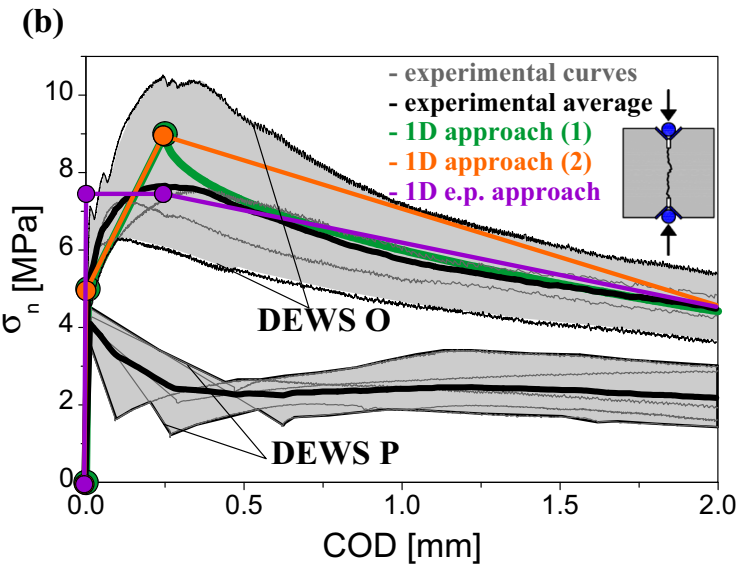

Fig. 5 Calibrated constitutive laws in direct tension (a) and $\sigma_{\mathrm{n}}-\mathrm{COD}$ curves from experimental tests and numerical analyses on specimens with ligament orthogonal (DEWS_O) and parallel (DEWS_P) to the fibres (b) 
(a)

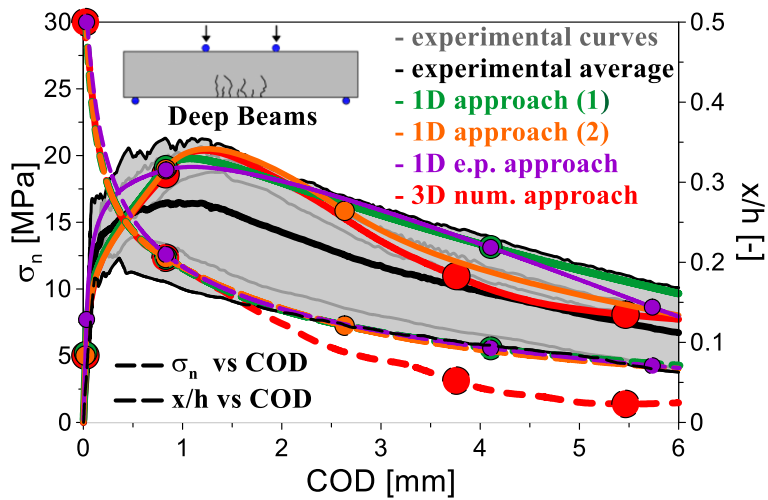

(c)

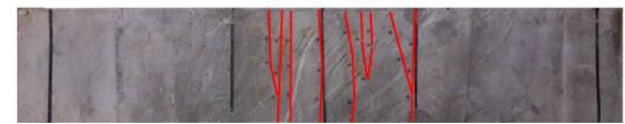

(b)

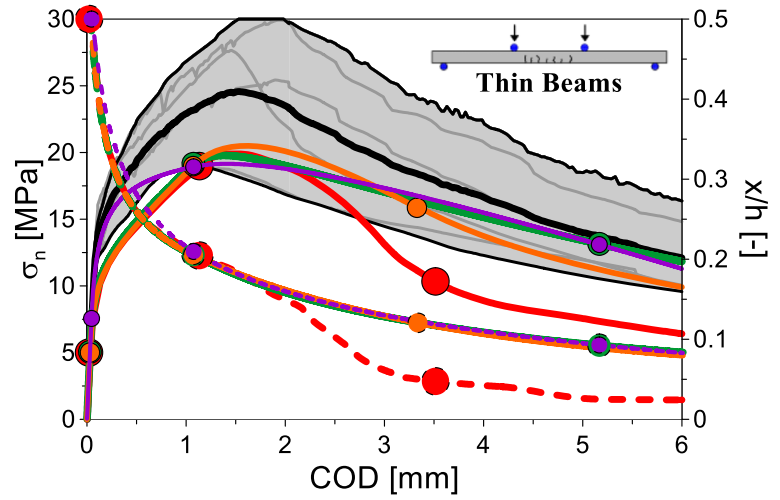

(d)

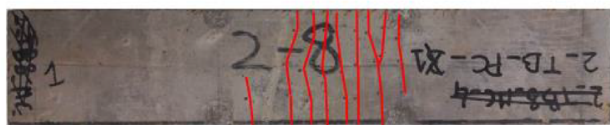

Fig. 6 4PBT: experimental and numerical $\sigma_{\mathrm{n}}-\mathrm{COD}$ curves for deep (a) and thin beams (b), together with the normalized neutral axis depth $\mathrm{x} / \mathrm{h}$, and typical cracking patterns in deep (c) and thin beams (d)

curves, for the case of fibres orthogonal (DEWS_O) or parallel (DEWS_P) to the ligament. COD is the average of LVDT measures, while the nominal stress $\sigma_{\mathrm{n}}$ is calculated as follows:

$\sigma_{n}=\frac{F_{\text {splitting }}}{A_{\text {ligament }}}=\frac{0.89 P}{A_{\text {ligament }}}$

where $P$ is the total load applied and $A_{\text {ligament }}$ is the net area of the ligament $\left(\approx 25.65 \mathrm{~mm}^{2}\right)$.

The coefficient 0.89 is a comprehensive coefficient accounting for both force equilibrium, which allows the vertical applied load $\mathrm{P}$ to be transformed into a splitting force normal to the ligament, and friction between loading devices and specimen [22].

The influence of fibre alignment on the tensile response of the fibre reinforced composites is evident, since in specimens with ligament orthogonal to fibre alignment (DEWS_O) a strain-hardening response is obtained, while for DEWS_P a tensile strain-softening behaviour is observed (since fibres parallel to the ligament hardly provide any sizable bridging across the crack).

The three reference $\sigma-\varepsilon$ and $\sigma-\mathrm{COD}$ curves adopted in the numerical analyses on 4PBTs (green, orange and violet curves in Fig. 5a) have been calibrated based on the experimental results on DEWS_O specimens, as shown in Fig. 5 b by the comparison among experimental and numerical curves.
In Fig. 6, the experimental $\sigma_{\mathrm{n}}-\mathrm{COD}$ curves related to 4PBTs on deep and thin beams are reported in grey and black colours together with the numerical curves. Comparing Figs. 5a and 6, the "structural effect" induced by sectional stress-redistribution in bending is clear, since the numerical curves of Fig. 6 are much smoother than the input constitutive laws of Fig. 5a, this being a direct consequence of stress re-distribution and sectional integration.

The nominal stress $\sigma_{\mathrm{n}}$ in $4 \mathrm{PBT}$ is evaluated as follows:

$\sigma_{n}=\frac{P L}{6} / \frac{b h^{2}}{6}=\frac{P L}{b h^{2}}$

where $P$ is the total load applied, $L$ is the distance between the two supports $(450 \mathrm{~mm}$ for both deep beams and thin beams), $b$ and $h$ are specimen width $(100 \mathrm{~mm})$ and height $(100 \mathrm{~mm}$ for deep beams and $25 \mathrm{~mm}$ for thin beams).

Looking into the experimental results, comparing the black curves of Fig. 6a and b (namely the average of the experimental curves) the effect of beam thickness is clearly evident, since a nominal peak stress generally $20-50 \%$ higher than in the case of deep beams is obtained from the tests on thin beams.

This evidence can be ascribed to two main reasons: (1) the well-known scale-effect (even significantly affecting concrete response depending on specimen 
geometry for both notched and un-notched samples [27-30]) and (2) the influence played by beam production on fibre alignment (as discussed in Sect. 2.2). Both these aspects cannot be caught by the implemented numerical analyses, in which the adoption of a general $\sigma-\varepsilon$ law in tension implicitly assumes the same fibre-distribution and scale-effect for all specimen geometries.

As regards the numerical results, it is interesting to observe that the tensile stress-strain curves identified from DEWS tests on thin square tile specimens returns back an upper-bound flexural response in the case of deep beams and a lower-bound one in the case of thin beams. This is coherent with previous findings $[22,26]$ and can be also explained considering that a slight downward segregation of the fibres always occurs also in highly rheologically stable mixes, as the ones herein investigated. Such a downward segregation positively affects the flexural response in thin beams, further enhanced by the alignment of the fibres, whereas is less significant, and anyway jeopardized by a random orientation of the fibres, in the case of deep beams.

Another interesting evidence is provided by the normalized neutral axis depth evaluated via the numerical analyses. It is worth noticing, in fact, as EC2 [31] recommends in liquid containment structures that normalized neutral axis depth is maintained higher than 0.2 , value which is achieved close to the peak of the loading curves in bending (mostly in correspondence of crack localization) shown in Fig. 6a and b.

This may also result in useful information when using the aforementioned data to design the intended UHDC structural applications, for which a "structural" identification of the tensile constitutive law may be required in the case of very thin elements, which the use of such high performance cementitious composites reliably allows.

The comparison among the numerical approaches shows no sizable difference among the four employed procedures, this being predictable for the first two approaches (where the adopted $\sigma-\varepsilon$ in tension is calibrated to match the experimental curves), while it is a rather interesting result for the third model, since it proves that a perfect-plastic model can satisfactorily describe the behaviour in bending, even though not closely approximating the strain-hardening response in direct tension (see Fig. 5b).
Finally, it can be observed as 1D simulations are in good agreement with the 3D modelling, even though a sharper softening branch can be observed in the latter case, especially for thin beams. This difference can be ascribed to the fact that, after the peak load is attained in 3D simulations, the strain tends to localize in a narrower band, while part of the specimen remains in the elastic unloading regime. The consequence is an overall more brittle behaviour. On the other hand, the adoption of a non-linear hinge in the multiple-cracking region for the 1D approaches translates into the assumption that the strain is constant along the specimen axis in the constant bending moment zone, without any elastic unloading. Similar consideration can be done regarding the variation of the normalized neutral axis depth, $x / h$ (see Fig. 6), where $x$ is measured from the most compressed side.

In Fig. $6 \mathrm{c}$ and d, two pictures show the typical cracking patterns in both deep and thin beams at the end of bending tests.

A summary of the experimental and numerical identification results reported in Figs. 5 and 6 is given in Table 2. Significantly, as the effect of the fibres tends to be exploited at its best in thin beam specimens (where the highest orientation is likely to be achieved), the average crack spacing approaches the length of the fibres, this being coherent with the through-crack stress transfer mechanism via fibre matrix bond.

\section{Concluding remarks}

The paper describes the mechanical characterization of the tensile constitutive response performed on an Ultra-High Durability Concrete (UHDC), namely an Ultra High-Performance Fibre-Reinforced Cementitious Composite (UHPFRCC) conceived for specific structural applications in extremely aggressive environments.

The characterization has been pursued by implementing an identification procedure based on the combination of experimental testing and numerical simulations, with the final aim of defining the main mechanical parameters describing the material behaviour in direct tension. Such scope is instrumental for moving from the experimental scale to the structural one, making possible a reliable structural design.

The experimental investigation has been performed by means of a set of "indirect tensile" tests, thought to 
Table 2 Experimental average, max and min values of mechanical properties of the mix, and main numerical input and output of the simulations

\begin{tabular}{|c|c|c|c|c|c|c|c|c|c|}
\hline \multicolumn{5}{|c|}{ Experimental results } & \multicolumn{5}{|l|}{ Numerical data } \\
\hline Parameters & Specimens & Avg & $\operatorname{Max}$ & Min & Parameters & 1D (1) & 1D (2) & 1D e.p. & 3D (1) \\
\hline$\sigma_{\mathrm{cr}}(\mathrm{MPa})$ & DEWS P & 4.2 & 4.5 & 3.8 & $\sigma_{\mathrm{cr}}(\mathrm{MPa})$ & 5.0 & 5.0 & 7.5 & 5.0 \\
\hline$f_{\mathrm{ct}}(\mathrm{MPa})$ & DEWS O & 8.0 & 10.5 & 6.4 & $f_{\mathrm{ct}}(\mathrm{MPa})$ & 9.0 & 9.0 & 7.5 & 9.0 \\
\hline$\sigma_{\mathrm{n}, \max }(\mathrm{MPa})$ & DB & 16.5 & 21.3 & 12.3 & $\sigma_{\max , \mathrm{DB}}(\mathrm{MPa})$ & 19.8 & 20.5 & 19.1 & 19.9 \\
\hline$\sigma_{\mathrm{n}, \max }(\mathrm{MPa})$ & TB & 24.6 & 30.7 & 18.8 & $\sigma_{\max , \mathrm{TB}}(\mathrm{MPa})$ & 19.8 & 20.5 & 19.1 & 20.4 \\
\hline Crack num. & $\mathrm{DB} \& \mathrm{~TB}$ & 7 & 12 & 2 & $\varepsilon_{\mathrm{p}}(\%)$ & 5.0 & 5.0 & 5.0 & 5.0 \\
\hline $\mathrm{R}_{\mathrm{c}}(\mathrm{MPa})$ & Cubes & 137 & 146 & 128 & $\mathrm{w}_{\mathrm{d}} / \mathrm{w}_{\mathrm{u}}(\mathrm{mm})$ & $-/ 6.75$ & $2.40 / 6.75$ & $-/ 4.50$ & $-/ 6.75$ \\
\hline $\mathrm{f}_{\mathrm{c}}(\mathrm{MPa})$ & $0.83 . \mathrm{R}_{\mathrm{c}}$ & 114 & 121 & 106 & E (GPa) & 41.7 & 41.7 & 41.7 & 41.7 \\
\hline
\end{tabular}

encompass simplicity in testing implementation and consistency in the results. To this end, Double Edge Wedge Splitting test method, developed at the authors' institution, and 4-Point Bending Tests on both $100 \mathrm{~mm}$ - and $25 \mathrm{~mm}$-thick beams (deep and thin beams, respectively), have been adopted. The latter ones have been especially designed to replicate the structural (fibre orientation-related) effects due to the low thickness, which has been foreseen in some specific applications.

The experimental results on bending tests, in fact, confirmed a remarkable difference in the flexural performance of thin beams as compared to deep beams, thanks to the effective alignment of steel fibres along the casting flow in the former case. Such difference is also favoured by scale-effect, leading to higher values of peak stress in the case of thin beams thanks to the reduced thickness.

The consistency of the experimental results coming from the different indirect tensile tests has been assessed numerically, by simulating the flexural tests on the basis of tensile constitutive laws calibrated starting from DEWS results. In particular, the average experimental stress-strain curve obtained from DEWS has been employed to firstly calibrate the constitutive material law in direct tension, which afterwards has been used to back simulate the flexural response obtained from tests on deep and thin beams.

The good agreement among numerical and experimental curves confirms the reliability of DEWS test to yield in a straightforward manner the tensile constitutive response of the composite. Interestingly, for the case of the steel-fibre reinforced UHDC mix herein presented, where strong fibre orientation was obtained in thin beams, the DEWS-identified tensile constitutive law returned a lower bound simulation of the flexural response of thin beams, and an upper bound one in the case of deep beams.

In order to investigate the influence played by some features of the constitutive law approximation, four different numerical analyses have been implemented: (1) 1D numerical approach based on sectional integration, (2) 1D analytical approach based on a quadrilinear law in tension, (3) 1D numerical approach with perfect-plastic law in tension and (4) 3D Finite Element modelling.

The different numerical approaches showed no sizable difference among each other, even comparing 1D sectional simulations and 3D finite element modelling, nevertheless a sharper softening branch can be observed in the latter case mostly due to a different crack localization mode after the load peak.

Furthermore, the approximation of the constitutive law with a perfect-plastic model (in the pre-localization branch) proved to be rather satisfactory. This is advantageous for the design of structures, since the adoption of a perfect-plastic law make much easier the structural analysis.

The identification procedure herein adopted, based on the cross-comparison of experimental results and numerical analysis, proved to be rather easy in implementation and effective in highlighting the overall consistency of the results.

This allows to confirm the strain-hardening tensile constitutive response of the investigated UHDC mix, with a tensile strength and a strain capacity adequate to be employed (even without any additional reinforcement) in the target final application of advanced design 
concept of cooling water basins in geothermal power plants, as foreseen by the pilot activity of the H2020 Project ReSHEALience.

Acknowledgements The research activity reported in this paper has been performed in the framework of the ReSHEALience project (Rethinking coastal defence and Green-energy Service infrastructures through enHancEddurAbiLity high-performance cement-based materials) which has received funding from the European Union's Horizon 2020 research and innovation program under Grant Agreement No. 760824. The information and views set out in this publication do not necessarily reflect the official opinion of the European Commission. The authors acknowledge the cooperation of MEng. Lorenzo Papa, Stefano Passoni, Angelo Alferi, Nicola Borgioni, Andrea Cervini and Luca Famiani in performing experimental tests, in partial fulfilment of the requirements for the MEng in Civil Engineering and Building Engineering respectively. The kind collaboration of ReSHEALience partner Penetron Italia (MArch. EnricoMaria Gastaldo Brac) in supplying the crystalline self-healing promoter is also acknowledged. The authors also thank Mr. Marco Francini (BuzziUnicem) for supplying of cement, Mr. Michele Gadioli and Roberto Rosignoli (Azichem ltd) for supplying of steel fibres and Mr. Sandro Moro (BASF Italia) for supplying the superplasticizer employed for casting the investigated UHDC mix.

Funding Open access funding provided by Politecnico di Milano within the CRUI-CARE Agreement. This study was funded by European Union's Horizon 2020 research and innovation program under Grant Agreement No. 760824.

\section{Compliance with ethical standards}

Conflict of interest The first author is member of RILEM Committee TC 256-SPF "Spalling of concrete due to fire: testing and modelling", while the second author is member of RILEM Committees TC SHE-Self healing evaluation in cement based materials, DFC-Digital fabrication with cement based materials and MRP-Measuring rheological properties of cement based materials.

Open Access This article is licensed under a Creative Commons Attribution 4.0 International License, which permits use, sharing, adaptation, distribution and reproduction in any medium or format, as long as you give appropriate credit to the original author(s) and the source, provide a link to the Creative Commons licence, and indicate if changes were made. The images or other third party material in this article are included in the article's Creative Commons licence, unless indicated otherwise in a credit line to the material. If material is not included in the article's Creative Commons licence and your intended use is not permitted by statutory regulation or exceeds the permitted use, you will need to obtain permission directly from the copyright holder. To view a copy of this licence, visit http://creativecommons.org/licenses/by/4.0/.

\section{References}

1. Serna P, Lo Monte F, Mezquida-Alcaraz EJ, Cuenca E, Mechtcherine V, Reichardt M, Peled A, Regev O, Borg RP, Tretjakov A, Lizunov D, Sobolev K, Sideri S, Nelson K, Gastaldo Brac EM, Ferrara L (2019) Upgrading the concept of UHPFRC for high durability in the cracked state: the concept of ultra high durability concrete (UHDC) in the approach of the $\mathrm{H} 2020$ project reshealience. In: Proceedings of the international conference on sustainable materials systems and structures SMSS 2019, Rovinj (Croatia), Mar 20-22, 2019, pp 764-771

2. Naaman AE, Reinhardt HW (2006) 'Proposed classification of HPFRC composites based on their tensile response. Mater Struct 39(5):547-555

3. Li VC, Wu HC (1992) Conditions for pseudo strain-hardening in fiber reinforced brittle matrix composites. Appl Mech Rev 45(8):390-398

4. Li VC, Stang H, Krenchel H (1993) Micromechanics of crack bridging in fibre-reinforced concrete. Mater Struct 26(8):486-494

5. Li VC (2003) On engineered cementitious composites. A review of the material and its applications. J Adv Concr Technol 1(3):215-230

6. Plagué T, Desmettre C, Charron J-P (2017) Influence of fiber type and fiber orientation on cracking and permeability of reinforced concrete under tensile loading. Cem Concr Res 94:59-70

7. Yang Y, Lepech M, Yang E, Li V (2009) 'Autogenous healing of engineered cementitious composites under wetdry cycles. Cem Concr Res 39:382-390

8. Zhang Z, Qian S, Ma S (2014) Investigating mechanical properties and self-healing behavior of micro-cracked ECC with different volume of fly ash. Constr Build Mater 52:17-23

9. Ferrara L, Ferreira SR, Krelani V, Della Torre M, Silva F, Toledo Filho RD (2015) Natural fibers as promoters of autogenous healing in HPFRCCs: results from on-going Brazil-Italy cooperation. Proceedings 1st International workshop on durability and sustainability of concrete structures, DSCS 2015; Bologna; Italy; 1-3 October 2015, ACI Special Publication Issue SP 305

10. Ferrara L, Krelani V, Moretti F (2016) Autogenous healing on the recovery of mechanical performance of HPFRCCs: part 2-correlation between healing of mechanical performance and crack sealing. Cem Concr Compos 73:299-315

11. Ferrara L, Krelani V, Moretti F, Roig Flores M, Serna Ros P (2017) Effects of autogenous healing on the recovery of mechanical performance of HPFRCCs: part 1. Cem Concr Compos 83:76-100

12. Snoeck D, De Belie N (2016) Repeated autogenous healing in strain-hardening cementitious composites by using superabsorbent polymers. ASCE J Mater Civ Eng 28(1):1-11

13. Baby F, Graybeal B, Marchand P, Toutlemonde F (2013) UHPFRC tensile behavior characterization: Inverse analysis of four-point bending test results Mater. Struct Constr 46:1337-1354 
14. Qian S, Li VC (2007) Simplified inverse method for determining the tensile strain capacity of strain hardening cementitious composites. J Adv Concr Technol 5:235-246

15. Soranakom C, Mobasher B (2007) Closed-form momentcurvature expressions for homogenized fiber-reinforced concrete. ACI Mater J 104:351-359

16. López JÁ, Serna P, Navarro-Gregori J, Camacho E (2015) An inverse analysis method based on deflection to curvature transformation to determine the tensile properties of UHPFRC. Mater Struct 48:3703-3718

17. Mezquida-Alcaraz EJ, Navarro-Gregori J, Serna-Ros $P$ (2019) Numerical validation of a simplified inverse analysis method to characterize the tensile properties in strain-softening UHPFRC. Fibre concrete 2019. Mater Sci Eng 596:012006. https://doi.org/10.1088/1757-899X/596/1/ 012006

18. López JÁ, Serna P, Navarro-Gregori J, Coll H (2016) A simplified five-point inverse analysis method to determine the tensile properties of UHPFRC from un-notched fourpoint bending tests. Compos B 91:189-204

19. MC 2010, fib model code for concrete structures 2010 , Comité Euro-International du Béton, Lausanne (Switzerland), 2012

20. Cuenca E, Criado M, Giménez M, Gastaldo Brac EM, Sideri S, Tretjakov A, Alonso MC, Ferrara L (2019a) Concept of ultra high durability concrete for improved durability in chemical environments: preliminary results. In: Conference on durable concrete for infrastructure under severe conditions-smart admixtures, self-responsiveness and nanoadditions, Ghent, Belgium

21. Cuenca E, Mezzena A, Ferrara L (2020) "Synergy between crystalline admixtures and nano-constituents in enhancing autogenous healing capacity of cementitious composites under cracking and healing cycles in aggressive waters". Constr Build Mater 121447

22. di Prisco M, Ferrara L, Lamperti MGL (2013) Double edge wedge splitting (DEWS): an indirect tension test to identify post-cracking behaviour of fibre reinforced cementitious composites. Mater Struct 46(11):1893-1918

23. Ferrara L, Bamonte P, Falcó CS, Animato F, Pascale C, Tretjakov A, Camacho ET, Deegan P, Sideri S, Gastaldo Brac EM, Serna P, Mechtcherine V, Alonso MC, Peled A,
Borg RP (2019) An overview on H2020 project "Reshealience". In: Proceeding IABSE symposium, guimaraes 2019: towards a resilient built environment risk and asset management (2019), pp 184-191

24. Ferrara L, Ozyurt N, di Prisco M (2011) High mechanical performance of fiber reinforced cementitious composites: the role of "casting-flow" induced fiber orientation. Mater Struct 44(1):109-128

25. Ferrara L, Faifer M, Toscani S (2012) A magnetic method for non-destructive monitoring of fiber dispersion and orientation in steel fiber reinforced cementitious compositespart 1: method calibration. Mater Struct 45(4):575-589

26. Ferrara L, Faifer M, Muhaxheri M, Toscani S (2012) A magnetic method for non-destructive monitoring of fiber dispersion and orientation in steel fiber reinforced cementitious composites-part 2: correlation to tensile fracture toughness. Mater Struct 45(4):591-598

27. Carpinteri A, Chiaia B, Ferro G (1995) Size effects on nominal tensile strength of concrete structures: multifractality of material ligaments and dimensional transition from order to disorder. Mater Struct 28:311-317

28. Yoo D-Y, Banthia N, Yang J-M, Yoon Y-S (2016) Size effect in normal- and high-strength amorphous metallic and steel fibre reinforced concrete beams. Constr Build Mater 121:676-685

29. Flàdr J, Bìly P (2018) Specimen size effects on compressive and flexural strength of high-strength fibre-reinforced concrete containing coarse aggregate. Compos B Eng 138:77-86

30. Accornero F, Rubino A, Carpinteri A (2020) Ductile-tobrittle transition in fiber-reinforced concrete beams: scale and fiber volume fraction effects. Mater Des Process Commun. https://doi.org/10.1002/mdp2.127

31. EC2, EN 1992-3 (2006) Eurocode 2: design of concrete structures-part 3: liquid retaining and containment. European Committee for Standardization (CEN), Brussels (Belgium), 2006

Publisher's Note Springer Nature remains neutral with regard to jurisdictional claims in published maps and institutional affiliations. 